\title{
Young Children's Perceptions of their Lives and Well-Being
}

\author{
Sabine Andresen ${ }^{1}$. Jonathan Bradshaw ${ }^{2}$. \\ Hanita Kosher ${ }^{3}$
}

Accepted: 30 March 2018 / Published online: 16 April 2018

(C) Springer Science+Business Media B.V., part of Springer Nature 2018

The field of children's own perceptions about their lives and well-being (subjective well-being) has evolved considerably over the last decade, on both the national and global levels. During that period, a growing number of studies have yielded extensive data on the topic (for example, Ash and Huebner 2001; Ben-Arieh and Frønes 2007; Ben-Arieh et al. 2014; Casas 2011; Gilman and Huebner 2003; Lee and Yoo 2015; Rees and Dinisman 2015). However, the research on children's subjective perceptions of their lives and well-being has focused primarily on middle childhood and adolescence (mainly children above 10 years of age), whereas research on the topic among younger children is limited. As a result, there is still a lack of knowledge about the subjective perceptions of life and well-being among children in this age group. For example, we don't know enough about what constitutes a good life from the perspective of young children, and what correlates with or affects their quality of life. One of the few studies conducted among this age group is the representative German Survey on subjective well-being, which examined children between 6 and 11 years of age (Andresen and Wilmes 2015; Andresen et al. 2017). This survey started in 2007 with 8 to 11 year olds, but from the second survey on, children aged 6 years and older were included as well. This was a household survey, and data were based on individual interviews. First, this design was important to ensure the validity of the data; second, it was easiest for the young age group.

Hanita Kosher

hanita.kosher@mail.huji.ac.il

1 Institute für Sozialpädagogik und Erwachsenenbildung, Goethe-Universität Frankfurt, Frankfurt am Main, Germany

2 University of York, York, UK

3 The Paul Baerwald School of Social Work and Social Welfare, The Hebrew University of Jerusalem, Jerusalem, Israel 
The limited number of studies on young children's subjective well-being could be attributed to misconceptions about the possibility of conducting research among young children. Moreover, for many years methodological as well as ethical concerns have restricted research on young children from their own perspective. These concerns relate to issues such as: can young children be a reliable source of information about their lives? Or could children's involvement in research expose them to harm and exploitation? In addition, concerns about the accuracy of young children's self-reports are evident in the literature (Bianchi and Robinson 1997; Plewis, Creeser and Mooney 1990). For many years, it was believed that data collected from young children are unreliable and invalid, mainly because young children were perceived as too immature to understand their own world, and as lacking the necessary verbal and conceptual abilities to express their thoughts and describe their experiences (Docherty \& Sandelowski 1999; Morrow 1999; Punch 2002). Furthermore, for many years, concerns about the ethics of conducting research among children in general and young children in particular led to the exclusion of children from studies on these topics and the use of adults as proxies (Beresford 1997). One concern relates to the researcher's responsibility and obligation to protect the well-being of participants, and to ensure that they are not abused or exploited in the process of research (for a full review see BenArieh and Kosher 2018).

Our experience in collecting data among children aged 8 years and older nevertheless shows that data can be obtained from young children, and that young children do have opinions and perceptions about their lives which they are very keen to share. This has also been acknowledged by several other scholars who have argued that although there are challenges related to measuring young children's perceptions about their lives, even young children are able to express themselves through a questionnaire (Bell 2007; Daly 2009). Thus, there is a growing body of knowledge about the accuracy, reliability, and importance of examining young children's perceptions about their lives (Andresen et al. 2017; Ben-Arieh and Kosher 2018; Sofer and Ben-Arieh 2014).

The substantial gap in research on the subjective well-being of children motivated us to collect the articles for this special issue, which focuses on young children's perceptions of their lives and well-being. In an attempt to fill this gap in our knowledge on young children's views of their own lives and well-being, the articles in the special issue provide new comparative insights into the context of children's lives and feelings. This evidence adds significant insights into children's lives in terms of the diversity of countries involved, the broad range of topics covered, and the age groups surveyed.

Initially, we aimed to publish studies based on the Children's Worlds Survey. Nevertheless, in the process of preparing the volume we were very happy to find out that there are several more initiatives which measure young children's lives and wellbeing around the world. Therefore this special issue became much larger in scope in terms of the age range of the children surveyed (from 4 to 9 years), as well as in terms of the topics and methodologies presented.

Seven out of eleven articles in this special issue are based on data from the second wave of the Children's Worlds Survey. Therefore it is important to provide some information about this important research project. Children's Worlds - the International Survey of Children's Well-Being (ISCWeB) project (http://www.isciweb.org/) is the first worldwide research project on children's subjective well-being. The project is based on the idea that one of the most important factors in assessing whether a 
particular environment is conducive to children attaining their best potential is the perception of their own sense of well-being. Thus, the survey is based solely on the children's own evaluations, perceptions, and aspirations. In the survey, children were asked about key aspects of their lives, including: their family and home life, friendships, money and possessions, school life, local area, time use, personal wellbeing, views on children's rights, and their overall happiness. The Children's Worlds survey is a profound example of data collection among young children (average age 8 years) throughout the world. More than 17,000 children aged 8 in 16 countries on four continents (Algeria, Colombia, England, Estonia, Ethiopia, Germany, Israel, Malta, Nepal, Norway, Poland, Romania, South Africa, South Korea, Spain, and Turkey) were asked about their life experiences and perspectives of their lives. Research of this nature among this age group is very unusual, and this is the most wide-ranging and diverse study ever to be conducted internationally on young children's lives from their own perspective. This remarkable achievement shows that first and foremost, children know better than anyone else about their lives, and that any effort to improve their well-being needs to include their voice (for a full review of the data on 8-year-olds see Rees et al. 2016).

The articles included in this special issue present diverse and advanced collections of research on young children's perceptions of their lives and their well-being. The articles focus on very young children ranging from about 4 to 9 years of age. They cover diverse issues and subjects relating to children's lives and well-being, from overall perceptions of their quality of life to their view about specific life domains such as scarcity, relationships with peers, family relations, safety, digital play, time use activities, their educational setting, etc. Some of the papers present an international view and compare children from different countries, whereas others focus on one specific country and cultural context. The volume also includes articles that present comparisons of children's versus parents' perspectives. Thus, we hope that this collection of articles will provide new insights into the world of young children from their own perspective.

Four of the articles present analyses of international databases that have produced knowledge on a large number of children from a wide range of countries. Some of the analyses also include comparisons of children from different countries. Cuartas and Rey-Guerra analyze the database of the Children's Worlds international project which, as noted, compares children from 16 countries. In their article they used a set of ecological predictors (individual characteristics and contextual factors) to analyze children's worries about family money (perceived scarcity). They found that the quality of family relationships, school climate, and peer involvement are the main predictors of children's tendency to worry about family money.

Melissa Reyes also uses the Children's Worlds international database to examine young children's subjective well-being in 11 countries. In her article, she examines the interactions between individual-level predictors and country-level moderators. The results of the study indicate that children who reported having more material resources and more adequate living spaces, as well as children who engage more frequently in worthwhile out-of-school activities, had higher levels of life satisfaction. Furthermore, the study revealed considerable cultural and national differences. For example, the findings indicate that the subjective well-being of children is more strongly predicted by safe and adequate living spaces in countries with a high inequality-adjusted human 
development index or in countries with collectivist cultures. This evidence points to similarities and differences across countries in the "pathways" that lead to children's subjective well-being.

Steckermeier also examines the subjective well-being of young children in 16 countries based on the Children's Worlds international database. The article explores the subjective well-being of children in relation to perceptions of safety and agency. The results show that children's agency and their perceived safety at home, in their neighborhood, and at school each contribute to their subjective well-being. More specifically, it was found that children's agency moderates the influence of safety on subjective well-being. The more satisfied children were with their agency, the less the feelings of being unsafe in the neighborhood harmed their well-being.

Raúl, Lee, Jiménez, and Cañamares also explore children's subjective perceptions of well-being from a cross-cultural perspective. Their study investigated satisfaction with and evaluations of different dimensions of life among children under age 9 in South Korea, Mexico, and Spain. It focused particularly on issues and implications associated with digital play and technologies, e.g., what do children enjoy and value more about digital play? What comparisons do they make between technological activities and more traditional experiences such as reading? What fears or worries do they associate with digital play or Internet surfing? In their study, the authors used unique methods of data collection which are appropriate for young children. These included conducting focus groups and collecting drawings from the participants. The findings of this study reveal interesting themes that may further strengthen qualitative research on the wellbeing of children under 9 years of age. It is also interesting to note that they found more similarities than differences among the participants from the three countries in beliefs about what is important for a good life.

Some of the articles provide insights into the subjective well-being of young children in specific countries. Migliorini, Tassara and Rania focused on the subjective well-being of eight-year-old Italian children. Their results shed light on the role of gender in the formation of subjective well-being among young children. Although no differences were found between males and females in overall subjective well-being, significant gender differences were found in the life domains of family and school. Moreover, the results reveal that gender contributed to moderating the relationship between school satisfaction and subjective wellbeing: higher satisfaction with school life was associated with higher subjective well-being for males but not for females.

Kim, Jaejin, and Joo-Lee explore the subjective well-being of children in South Korea. Their aim was to examine possible differences in perceived well-being among 8 -year-old children versus children aged 10 and 12 . They also explored the differences in the roles that family, school, and community play in the subjective well-being of children in the different age groups. Their study showed that the effects of these factors on the subjective well-being of 8-year-olds were different from their effects on the subjective well-being of 12-year-olds. The results indicate that satisfaction with freedom and "relationships with friends" correlated significantly with the subjective wellbeing of young children. These variables had a stronger effect on 8-year-olds than on 12-year-old children. In contrast, "satisfaction with school marks" significantly influenced subjective well-being, and had a stronger effect on 12-year-old children than it did on 8-year-old children. 
In this volume, Rees incorporates a longitudinal study that has been lacking in much of the research in this field. He uses the data from Wave 4 of the Millennium Cohort Study in the UK, which was a birth cohort study conducted among a large representative sample of children in the UK born near the start of the new millennium. This study began with the first sweep, when the children were nine months old. Several subsequent sweeps have been undertaken so far, when the children were around three, five, seven, 11 and 14 years of age, respectively. The data analyzed in this article focus on the first and fourth sweeps, which included about 13,000 7-year-old children and their parents. The analysis set out to explore which factors in the lives of the children at age 7 predicted their affective subjective well-being, and whether factors in earlier childhood could predict the children's subjective well-being at 7 years of age. The results of this study indicate that family, socio-economic, and parent-reported factors explained relatively little of the variance in the children's affective subjective wellbeing at age 7 . Rather, other information that the children reported about their views of their relationships with friends and family and issues of safety, bullying, and social exclusion at school played a more important role. The findings also reveal that early childhood circumstances did not have predictive power in terms of children's subjective well-being at age 7 .

Two articles attempt to incorporate a children's rights approach to understanding children's subjective well-being. Kutsar, Soo, Strózik, Strózik, Grigora, and Bălătescu attempt to demonstrate the relationships of the indicators of subjective well-being in a rights framework (such as feeling safe, being heard and cared for, and being treated fairly) to children's subjective perceptions of good life. Their sample included over 8000 eight-year-old children from eight European countries, based on the Children's Worlds international database. The analysis revealed that provision (being cared for) and protection (feeling safe) are the leading determinants of a good life in children's perspectives, whereas participation (being heard and listened to) and nondiscrimination (being treated fairly) are the most diverse determinants of a good life across countries.

Ursin and Haanpää examine the understanding of children of their rights and their opinions about respect for their rights in 16 countries, based on the Children's Worlds international database. They found that although a minority of the children were aware of children's rights and knew about their rights, the majority felt that their rights were respected. There was considerable variation in the children's responses by country, in every dimension of the rights investigated. Depending on the country, children's rights outcomes were most powerfully explained by three indicators: family deprivation, and home and school climates. The lower the deprivation score was and the stronger the children's perceptions of being heard at home and at school, the more aware they were, the more knowledge they had, and the more they perceived adults as respecting children's rights.

Three of the articles in this volume focus on very young children (aged 4-6). These contribution of these papers to the topic is noteworthy, considering that there are very few studies in which very young children themselves are asked about their well-being. Vieira, Formiga, and Linhares investigated 83 Brazilian children of preschool age (mean age 5 years), as well as their primary caregivers. They examined the association between the perceptions reported by the primary caregivers (parent-reports) and the children's self-reports on their quality of life. Their results show that the primary 
caregivers' perceptions and the children's perceptions of their quality of life at preschool age did not correlate with each other. The article highlights the need to investigate children's own perceptions of their well-being, which are different from those of their parents.

Sandseter and Seland focus on young children's well-being in early childhood education and care institutions from their own point of view. The findings show how 4-6-year-old children experience their lives in early childhood education and care institutions. Specifically, the study aimed to explore how children experience their social relations with other children and staff in their early childhood education and care institutions, and how these experiences are related to their general subjective wellbeing. The results indicate that relationships with other children as well as with the practitioners are important for children's well-being. In particular, it is important that they like the other children and feel that the children are kind to each other.

Strijbosch, Van der Helm, Stams, and Wissink conducted their study among 116 children in Dutch (semi)residential youth care settings in the Netherlands. Their aim was to describe the development and validation of the Group Climate Instrument for Children aged 4-8, which aims to measure the quality of group climate, based on the views of the young children themselves. The study proved that the tool can be used to measure positive and negative aspects of group climate in (specialized) group care.

To summarize, in this special issue we would like to provide an overview of a fascinating and innovative field of research, and encourage scholars to look more closely into young children's subjective perceptions of their well-being.

\section{References}

Andresen, S., \& Wilmes, J. (2015). What does 'good childhood' in a comparative perspective mean? An explorative comparison of child well-being in Nepal and Germany. Child Indicators Research, 8, 33-48.

Andresen, S., Fegter, S., Hurrelmann, K., \& Schneekloth, U. E. (2017). Well-being, poverty and justice from a Child's perspective. In 3rd world vision children study. Dordrecht: Springer.

Ash, C., \& Huebner, E. S. (2001). Environmental events and life satisfaction reports of adolescents. School Psychology International, 22, 20-36.

Bell, A. (2007). Designing and testing questionnaires for children. Journal of Research in Nursing, 12(5), 461-469. https://doi.org/10.1177/17449871079616.

Ben-Arieh, A., \& Frønes, I. (2007). Indicators of children's well-being: What should be measured and why? Social Indicators Research, 84, 249-250. https://doi.org/10.1007/s11205-007-9183-6.

Ben-Arieh, A., \& Kosher, H. (2018). The child study movement. In Encyclopedia of Child and Adolescent Development. Wiley publication.

Ben-Arieh, A., Casas, F., Frønes, I., \& Korbin, J. E. (2014) (Eds.). Handbook of child well-being: Theories, methods and policies in global perspective. Springer Netherlands.

Beresford, B. (1997). Personal accounts: Involving disabled children in research. York: Social Policy Research Unit.

Bianchi, S. M., \& Robinson, J. (1997). What did you do today? Children's use of time, family composition, and the acquisition of social capital. Journal of Marriage and the Family, 59, 332-344.

Casas, F. (2011). Subjective social indicators and child and adolescent well-being. Child Indicators Research, 4, 555-575. https://doi.org/10.1007/s12187-010-9093-z.

Plewis, I., Creeser, A. and Mooney, R. (1990). Reliability and validity of time budget data: children's activities outside school. Journal of Official Statistics, 6, 411-419.

Daly, W. (2009). Adding their flavour to the mix: Involving children and young people in care in research design. Australian Social Work, 62, 460-475. https://doi.org/10.1080/03124070903265732.

Docherty, S., \& Sandelowski, M. (1999). Focus on qualitative research methods. Interviewing children. Research in Nursing and Health, 22, 177-185. 
Gilman, R., \& Huebner, S. (2003). A review of life satisfaction research with children and adolescents. School Psychology Quarterly, 18, 192-205. https://doi.org/10.1521/scpq.18.2.192.21858.

Lee, B. J., \& Yoo, M. S. (2015). Family, school and community correlates of Children's subjective well-being : An international comparative study. Child Indicators Research, 8(1), 151-175. https://doi.org/10.1007 /s12187-014-9285-z.

Morrow, V. (1999). We are people too: Children's and young people's perspectives on children's rights and decision-making in England. The International Journal of Children's Rights, 7, 149-170.

Punch, S. (2002). Research with children the same or different from research with adults?. Childhood, 9, 321341.

Rees, G., \& Dinisman, T. (2015). Comparing children's experiences and evaluations of their lives in 11 different countries. Child Indicators Research, 8, 5-31.

Rees, G., Andresen, S. \& Bradshaw, J. (Eds.) (2016). Children's views on their lives and well-being in 16 countries: A report on the Children's Worlds survey of children aged eight years old, 2013-15. York, UK: Children's Worlds Project (ISCWeB). Retrieved from http://isciweb.org/_Uploads/dbsAttachedFiles/8 yearsoldreport.pdf

Sofer, M., \& Ben-Arieh, A. (2014). School-aged children as sources of information about their lives. In G. Melton, A. Ben-Arieh, J. Cashmore, G. Goodman, \& N. Worley (Eds.), The SAGE handbook of child research (pp. 555-575). London: SAGE. 